\title{
Waarom Moslims wel democratische attitudes hebben maar geen democratische instituties
}

Article in Res Publica · January 2010

CITATIONS

0

2 authors:

André Van Hoorn

Radboud University Nijmegen

43 PUBLICATIONS 210 CITATIONS

SEE PROFILE
READS

3
Robbert Maseland

University of Groningen

40 PUBLICATIONS 250 CITATIONS

SEE PROFILE 


\title{
Waarom Moslims wel democratische attitudes hebben maar geen democratische instituties
}

\author{
Robbert Maseland en André van Hoorn
}

\begin{abstract}
SAMENVATTING VAN
Maseland, R. \& van Hoorn, A. (2010). Why Muslims like democracy yet have so little of it. Public Choice, doi:10.1007/s11127-010-9642-5.
\end{abstract}

In de Islamitische wereld zijn democratische instituties relatief schaars. Tegelijkertijd toont onderzoek aan dat attitudes ten aanzien van democratie onder Moslims en in Islamitische landen niet minder positief of zelfs positiever zijn dan elders. Dit resultaat vormt een onopgeloste puzzel voor onderzoekers die verwachten dat politieke instituties deels een gevolg zijn van culturele ideeën en preferenties van een bevolking.

In dit artikel geven we een verklaring voor deze (schijnbare) paradox. Aan de hand van de Moslim-democratie paradox laten we zien dat culturele verklaringen voor sociaal-politieke uitkomsten potentieel problematisch zijn, vooral daar waar de empirische cultuur maatstaven gebaseerd zijn op data uit zogenaamde waarden-enquêtes. Vaak blijkt dat attitudes gemeten met dit soort enquêtes juist een reflectie zijn van verschillen in omstandigheden in plaats van een onderliggende oorzaak daarvan. Deze bevinding biedt een logische verklaring voor het negatieve verband tussen democratische instituties en attitudes onder Moslims: mensen hechten de meeste waarde aan datgene wat schaars is. Omdat Moslims gemiddeld genomen een gebrek aan democratie ervaren, hebben ze een sterkere wens voor meer democratische instituties. Daarentegen is onder mensen wier behoefte aan democratie al meer bevredigd is, het verlangen naar democratie zwakker. Hier is niets paradoxaals aan.

De interesse in Moslim-attitudes ten aanzien van democratie past binnen de bredere onderzoekstrend in de politieke en economische wetenschappen die kijkt naar cultuur om politiek-economische uitkomsten te verklaren (zie Beugelsdijk en Maseland, 2010 voor een beschouwing van deze literatuur). Sinds Huntington's (1993) controversiële ‘clash of 
civilizations' these is de aandacht voor culturele en religieuze verschillen sterk gegroeid. De compatibiliteit van 'de' Islam met 'Westerse' normen en waarden heeft daarbij speciale belangstelling.

Veel onderzoek op dit terrein gebeurt op basis van (landenvergelijkende) waarden-enquêtes zoals de World Values Survey (e.g. Inglehart, 1997). De idee achter waarden-enquêtes is simpel: vraag aan een groot aantal respondenten hoe zij tegenover een aantal zaken staan, en aggregeer hun antwoorden om te komen tot maatstaven van culturele verschillen tussen samenlevingen. In het eigen werk van Inglehart ligt de nadruk op het blootleggen van verschillen tussen culturen en worden de resultaten niet zozeer gebruikt om verschillen in uitkomsten te verklaren. De secundaire literatuur die dat wel doet baseert zich doorgaans op de simpele veronderstelling dat antwoorden in waarden-enquêtes de culturele attitudes van mensen weergeven, die op hun beurt als basis dienen voor het feitelijk handelen van individuen en samenlevingen als geheel. Op deze manier zou bijvoorbeeld een democratisch tekort in Islamitische samenlevingen teruggebracht kunnen worden tot een culturele voorkeur voor autocratische regimes.

Bij deze redenering moeten een aantal kanttekeningen geplaatst worden. We noemen er hier twee. Ten eerste is het twijfelachtig of cultuur inderdaad zo bepalend is voor menselijk handelen. Vanuit de hoek van rationele keuzetheorie is er om deze reden bezwaar tegen een deterministische visie op cultuur (referenties). Een tweede bezwaar dat in de literatuur naar voren komt draait om de vraag of de theoretische conceptualisering van waarden in culturele verklaringen - als een diepliggende, door de samenleving vastgelegde bron van voorkeuren en handelingen - wel overeenkomt met wat waarden-enquêtes feitelijk meten (Maseland en van Hoorn, 2009, 2010). Een alternatieve lezing van scores uit waarden-enquêtes is dat ze niet zozeer waarden weergeven als wel marginale preferenties, het belang dat mensen hechten aan meer van een doel, bijvoorbeeld meer democratie, bovenop het huidige niveau.

Dit perspectief is van belang voor het empirische verband tussen waardenscores en uitkomsten. Culturele verklaringen veronderstellen een positief verband tussen deze scores en uitkomsten; een marginale preferentie-interpretatie daarentegen suggereert een negatief verband. De logica is simpelweg dat het belang dat men hecht aan het verder nastreven van een bepaald doel afneemt met de verwerkelijking van dat doel. Dit is het welbekende principe van afnemend grensnut, een van de meest robuuste fenomenen in de sociale wetenschap. 
In dit onderzoek tonen we op basis van een multi-level analyse van het verband tussen democratische instituties en attitudes (gemeten volgens de WVS) aan dat dit verband in het algemeen negatief is, en dus niet alleen voor Moslims (zie tabellen 3 tot en met 5 in het artikel). Dit resultaat verandert niet als we controleren voor nationaal inkomen per hoofd en individuele kenmerken zoals opleidingsniveau. We concluderen dat de WVS scores voor de houding ten aanzien van democratie geen cultureel bepaalde waarden meten, maar de marginale preferentie voor democratie en daarmee het feitelijke niveau van democratie in landen weergeeft. Degenen die in democratisch landen wonen hechten weinig belang aan democratie, terwijl degenen die democratie moeten ontberen een sterk positieve visie op democratie hebben. In deze zin is er dus helemaal geen Moslim-democratie paradox.

Daarmee willen we niet beweren dat culturele verschillen niet belangrijk zijn in het verklaren van sociaal-politieke uitkomsten. Wel toont de schijnbare Moslim-democratie paradox aan dat we voorzichtig moeten zijn om verschillen in voorkeuren die mensen uiten al te snel als cultureel of religieus te bestempelen. Veel van de verschillen die uit waarden-enquêtes naar voren komen lijken eerder het resultaat van verschillen in omstandigheden dan van cultuur. Deze bevindingen tonen de noodzaak van een kritische blik op kwantitatief onderzoek naar culturele verschillen aan.

\section{Bibliografie}

Beugelsdijk, S. \& Maseland, R. (2010). Culture in Economics. History, Methodological Reflections, and Contemporary Applications. Cambridge University Press, te verschijnen.

Huntington, S.P. (1993). The clash of civilizations. Foreign Affairs, 72 (3), 22-50.

Inglehart, R. (1997). Modernization and Postmodernization: Cultural, Economic, and Political Change in 43 Societies. Princeton: Princeton University Press.

Maseland, R. \& van Hoorn, A. (2009). Explaining the Negative Correlation between Values and Practices: A Note to the Hofstede-GLOBE Debate. Journal of International Business Studies, 40 (3), 527-532.

Maseland, R. \& van Hoorn, A. (2010). Values and Marginal Preferences in International Business. Journal of International Business Studies, doi:10.1057/jibs.2010.24. 


\section{AUTEURSINFO}

Robbert Maseland $\left({ }^{\circ} 1975\right)$ is als universitair docent verbonden aan de faculteit economie \& bedrijfskunde van de Rijksuniversiteit Groningen. Hij doet onder meer onderzoek naar... Email: R.K.J.Maseland@rug.nl

André van Hoorn $\left({ }^{\circ} 1976\right)$ is als universitair docent verbonden aan de faculteit economie \& bedrijfskunde van de Rijksuniversiteit Groningen. Zijn onderzoeksinteresses betreffen onder andere de comparatieve studie van geluk en subjectief welzijn, van cultuur en (in)formele instituties, en van economische groei en innovatie. E-mail: A.A.J.van.Hoorn@rug.nl. 